\title{
Research on the building restoration engineering and materials of the Night Watch House in Macau - taking the Patane Night Watch House in Patane as an example
}

\author{
Yile Chen ${ }^{1, *}$, Junrui $\mathrm{Cao}^{1,2}$, and Liang Zheng ${ }^{1}$ \\ ${ }^{1}$ Macau University of Science and Technology, Avenida Wai Long Taipa Macau, China \\ ${ }^{2}$ Industrial Design Institute, Zhao Qing University, Zhao Qing, China
}

\begin{abstract}
As the only existing example of the Night Watch House building in Guangdong, Hong Kong and Macau, the Patane Night Watch House has become one of the common cultural relic building restoration methods and revitalization design ideas in Macau. Study and explore the restoration problems from four aspects: the historical development of the Macau Museum, the construction context, the Lingnan architectural characteristics, the methods and materials of the restoration project, and hope that this will be used as a follow-up of similar types of buildings in Macau and the Lingnan Cantonese area to provide some experience reference.
\end{abstract}

\section{Introduction}

The Patane Night Watch House (Portuguese: Posto do Guarda-Nocturno no Patane) is located at no. 52-54 in Rua da Palmeira, Freguesia de Santo António, Macau. The typical Lingnan Cantonese residential building, after the baptism of history and the restoration project led by the Macau Cultural Affairs Bureau, was officially opened in December 2015. It is currently the only existing building in Guangdong, Hong Kong and Macau and belongs to the Macau Cultural Bureau. The list of "assessed real estate (architectural relics)" included in the category is "memorials", which is specifically used to introduce and showcase Macau night watch culture [1].

The Patane Night Watch House was part of an ensemble of similar houses, and comprised two single-storey compartments, with gabled roofs, separated by an inner patio $[2,3]$. The rear compartment incorporated in its construction an existing large stone, on top of which wooden columns and a brick wall were built. This style of houses, built close to the hillside, embody an architecture that is adapted to the geography of the surrounding area, bringing together the natural and cultural landscapes [4].

The exhibition covers two themes, namely the various night watch houses existing in Macau and the night watchmen's profession itself. It showcases, through historical photos, the exhibition of objects, the architecture of the night watch house after its renovation, and

\footnotetext{
* Corresponding author: chenyile1996@163.com
} 
with an artist's graphic illustrations, the status, transformation and evolution of this energetic occupation.

The Patane Night Watch House covers an area of about 63 square meters and is only one storey high. It should be part of a row-style residential building. The architectural form of the traditional Cantonese residential building is basically the same as the bamboo tube house with a surface width of about 6 meters. The depth is between 11 and 12 meters, it is divided into a front seat and a rear seat. It is a single-bay three-entry type. The front seat has a singlesloping tile roof, and the two behind the central patio are double-sloped tile roofs. Both are common styles of Lingnan residential buildings.

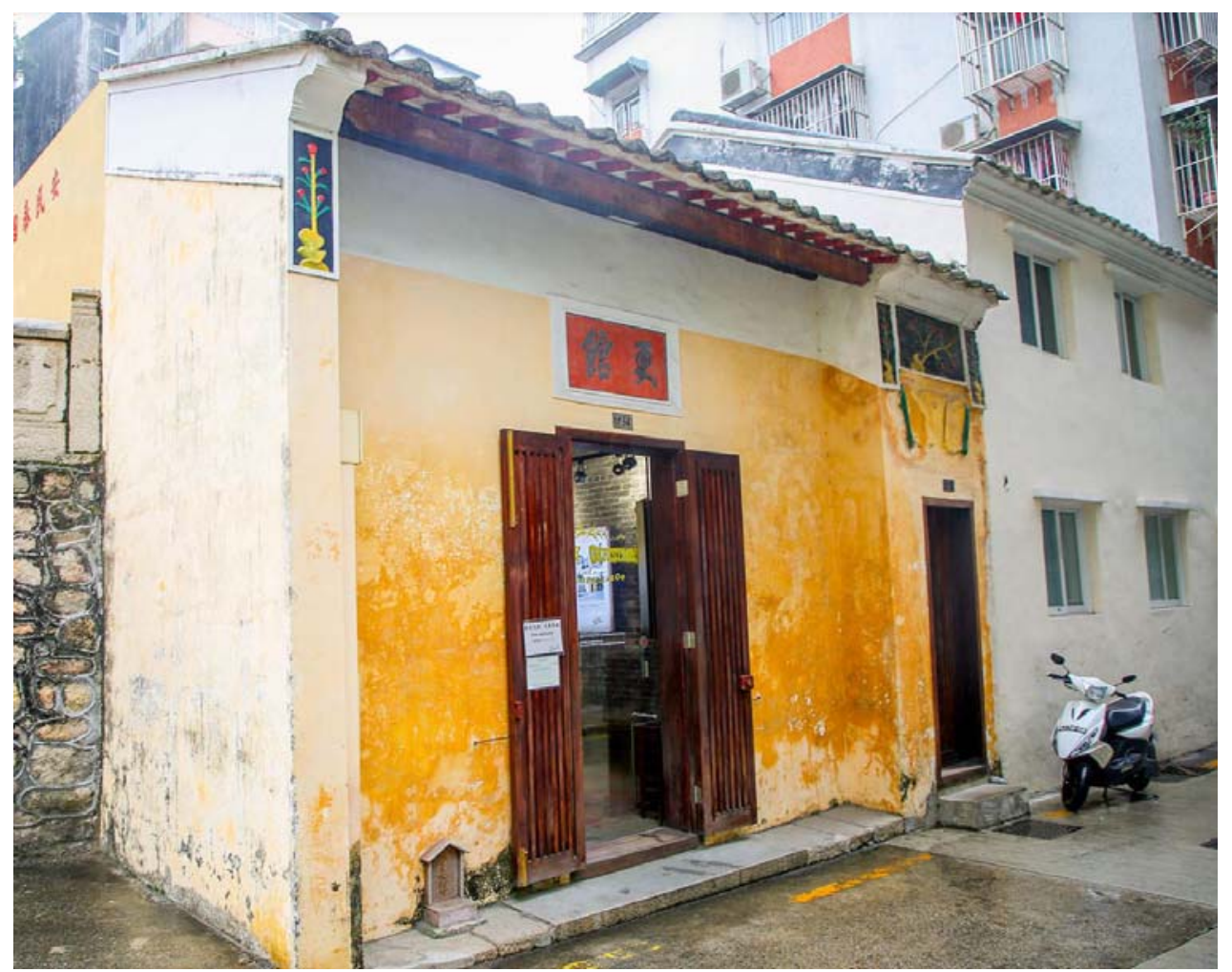

Fig. 1. Exterior of The Patane Night Watch House.

The restored museum is equipped with two themed exhibitions of "Macau Renewal" and "Reinforced Image". Historical photos, physical exhibits, restored museum buildings, and artist's image creation are used to present the profession's profession Form and changes. At present, the scope of buildings normally used for use includes single-bay bungalows, patios, stone chambers and Qingyun Lane. The main building uses are exhibition venues, and a small part is used to store objects.

\section{Repair engineering and material application}

\subsection{Repair of building facades: latex paint}

Compared with the water-polished blue bricks on the original walls of the Patane Night Watch House, the facade of the building was painted with yellow latex paint during the restoration process, which kept the same as the yellow, red, green and other Portuguese-style 
buildings in the Rua da Ribeira do Patane area. The appearance of the city is coordinated, but only the appearance is consistent with the original. The difference in materials has caused local damage to the building.

Latex paint is a type of water-based paint prepared by adding pigments, fillers and various additives to synthetic resin emulsion as a base material. It is also called synthetic resin emulsion paint and is a kind of organic paint. According to the different production materials, latex paint mainly includes polyvinyl acetate latex paint, ethylene propylene latex paint, pure acrylic latex paint and other varieties. According to the application environment of the product, it can be divided into two types: interior wall and exterior wall latex paint. The gloss effect can be divided into matte, matte, semi-gloss, mercerized and glossy.

The advantage of using latex paint on the wall is that it has a wide variety of colors, soft color, good coverage, can extend and cover small cracks; good adhesion, easy to manage and clean, etc., and the construction is simple and convenient.

The general process steps for the restoration of the facade of the ancient building are:

(1) For the parts that are peeled, cracked or even fall off on the facade of the old building, clean up first to ensure that the old wall is clean;

(2) Spread the putty layer before applying latex paint. If you are using glutinous rice map plant paint, you can omit the step of brushing the putty layer and apply the paint directly;

(3) Then come to the step of sanding the wall. The sandpaper used for sanding needs to be selected according to the hardness of the putty. If the putty is softer, you can choose No. 400-500 sandpaper. If the putty is harder, you can choose No. 360-400 sandpaper;

(4) Then you can apply primer or glutinous rice map plant paint. If the wall space is larger, the amount of wall paint will be larger. In this case, you can add an appropriate amount of water to the primer. As for glutinous rice map plant paint. The water is added in a certain proportion. During the painting process, the primer should be evenly applied to every part of the wall;

(5) Paint the part of the wall that needs to be filled.

\subsection{The original facade material: paper strip mixed lime mortar}

In the last century, paper strip mixed lime mortar was used to paint the facades of buildings to wrap the bricks inside, as well as British clay (local building materials in Guangdong, Hong Kong and Macau) and lime. Generally speaking, paper strip mixed lime mortar is a mixture of paper-reinforced and lime, which is a kind of material processed into a slurry with grass or fibrous material. It is evenly mixed into the plastering mortar in proportion, and the whole is viscous. Prevent cracks in the plastering layer of the wall, increase the connection strength and consistency of the mortar, and the bulk density including the base ash is generally $33 \mathrm{KN} / \sim 35 \mathrm{KN} /$. However, paper strip mixed lime mortar is not slaked lime. "Paperreinforced ash" is made of white paper or straw paper, which should be soaked, mashed and cleaned with water before use; the paper reinforces should be finely ground with a machine. Straw and wheat straw should be tough, dry, free of impurities, and their length should not be greater than $30 \mathrm{~mm}$, and they need to be soaked in lime slurry. In this area, the use of paper strip mixed lime mortar can play a role in moisture and heat insulation [5]. 


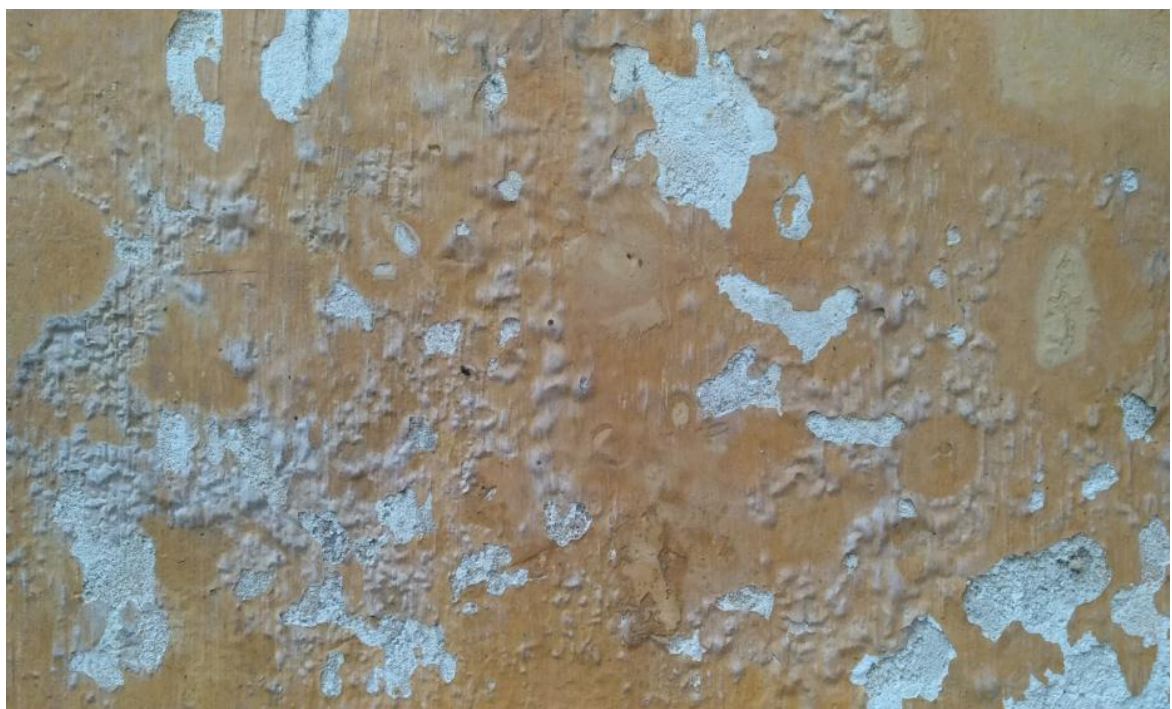

Fig. 2. Facade with blistering and falling off.

\subsection{Existing problems after the restoration of the facade: bubbling on the wall, air flow vortex}

Macau belongs to the southern part of the Lingnan region. It has a subtropical maritime monsoon climate with hot summers and warm east, and there are still southern days throughout the year. It is relatively humid. The humidity in the air is high at ordinary times, and the building facade needs to be "ventilated". It can be seen from the on-site inspection of the facade of the pavilion that the wall has fallen off, and there are some bumps and blisters. This is because latex paint is not breathable, and when the building needs to "breath" and "breath", the "air" generated will push the latex paint out, causing it to fall off and foam.

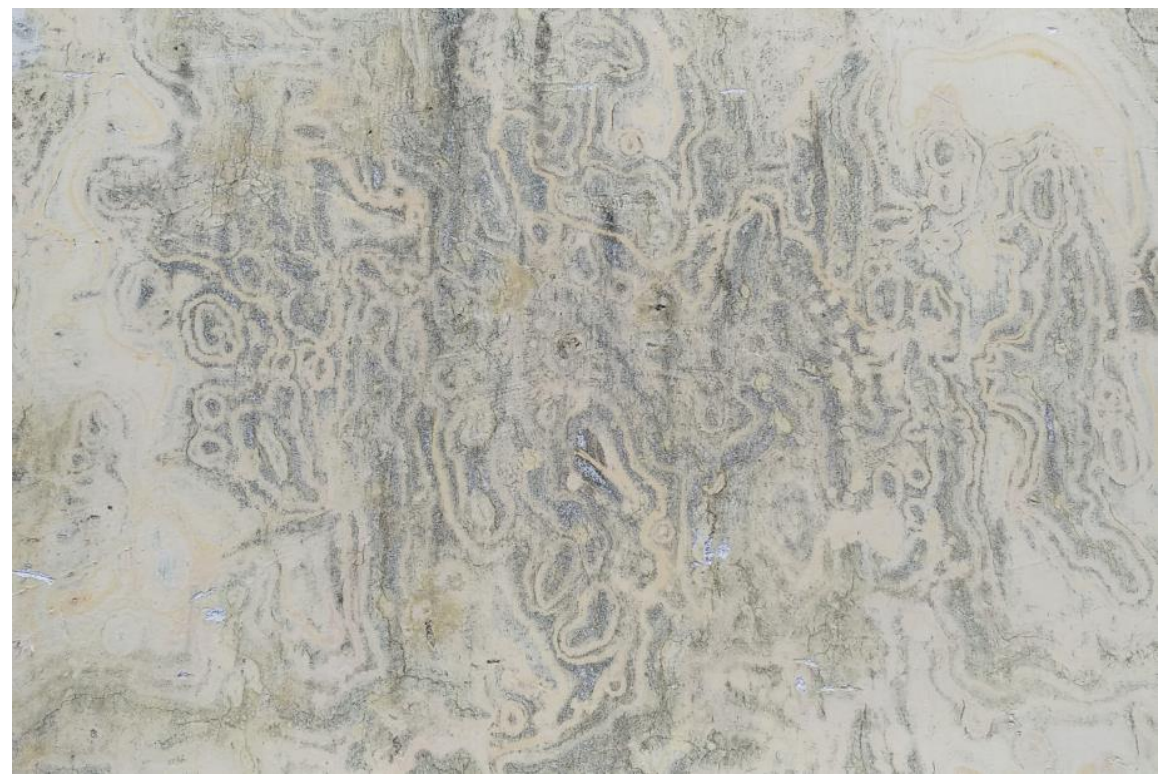

Fig. 3. Vortex traces on the windward side. 
At the same time, the west façade of the pavilion belongs to the windward side, and the roof and side stone walls are all subjected to wind suction. The airflow swirls between the eaves on the windward side and the wall, and then forms a whirlpool after separation. The dust in the vortex and the whirlpool formed traces of different shades of black and gray on the wall, which were difficult to clean [6].

\section{Summary}

The Patane Night Watch House is the only remaining building in Guangdong, Hong Kong and Macau, which embodies the architectural features of the traditional residences of Cantonese in Lingnan. However, due to improper use of materials in the restoration project, the facade of the building was obviously damaged. It is recommended that in the follow-up periodical repair process, the common "bottom-probing method" of cultural relic restoration should be used first, a small part of the excavation knows the material composition inside, and the repair should be carried out according to the method of "repair as old as old" using the ratio of raw materials. At the same time, the latex paint that damages the exterior wall of the building should be removed until the brick layer is seen, and then the grass or paper reinforcement ash should be added. Being good at adapting to local climate conditions and environment, and choosing building restoration materials can the building be preserved for a longer time.

\section{References}

1. Wang Wenda, The History of Macau (Macau Education Press, Macau, 2003)

2. https://www.culturalheritage.mo/cn/detail/2696

3. https://www.gov.mo/zh-hans/news/121397/

4. Value-added waste latex paints in masonry cement for plastering applications. Journal of Adhesion Science and Technology 34(24) (2020)

5. L. Jong, Materials Today Communications 23 (2020)

6. https://www.archives.gov.mo/webas/ArchiveDetail2016.aspx?id=75260 